\title{
Bismuth (III) Chloride Catalyzed Multicomponent Synthesis of Substituted Hexahydroimidazo[1, 2-a]Pyridines
}

\author{
Noah T. Haskin', Richard A. Guingrich¹, Allison J. Schrader'1, Matthew R. Crosse1, Alpa Y. Dave², \\ Eeshwaraiah Begari ${ }^{2}$, Ram S. Mohan ${ }^{1 *}$ \\ ${ }^{1}$ Laboratory for Environmentally Friendly Organic Synthesis, Department of Chemistry, Illinois Wesleyan University, \\ Bloomington, IL, USA \\ ${ }^{2}$ Centre for Applied Chemistry, School of Applied Material Sciences, Central University of Gujarat, Gandhinagar, India \\ Email: ^rmohan@iwu.edu
}

How to cite this paper: Haskin, N.T., Guingrich, R.A., Schrader, A.J., Crosse, M.R., Dave, A.Y., Begari, E. and Mohan, R.S. (2021) Bismuth (III) Chloride Catalyzed Multicomponent Synthesis of Substituted Hexahydroimidazo[1, 2-a]Pyridines. Green and Sustainable Chemistry, 11, 89-95. https://doi.org/10.4236/gsc.2021.113008

Received: July 14, 2021

Accepted: August 2, 2021

Published: August 5, 2021

Copyright $\odot 2021$ by author(s) and Scientific Research Publishing Inc. This work is licensed under the Creative Commons Attribution International License (CC BY 4.0).

http://creativecommons.org/licenses/by/4.0/

\begin{abstract}
The synthesis of nitrogen containing heterocycles is of particular interest in the pharmaceutical industry due to the range of biological activities exhibited by such compounds. Their synthesis using multicomponent reactions saves steps and minimizes waste generation. The bismuth (III) chloride multicomponent synthesis of a series of hexahydroimidazo[1,2-a]pyridines is reported. Bismuth (III) compounds are especially attractive from a green chemistry perspective because they are remarkably nontoxic, non-corrosive and relatively inexpensive. The reported method avoids chromatography and an aqueous waste stream to afford the products in a very mass efficient manner.
\end{abstract}

\section{Keywords}

Bismuth Chloride, Green Chemistry, Heterocycles, Multicomponent Reactions

Heterocyclic rings are a common structural feature seen in many pharmaceuticals and their facile construction has been a subject of study for many decades [1] [2]. Nitrogen containing heterocycles in particular are among the most versatile motifs, and hence significant efforts have been directed towards developing methods for their efficient synthesis [3]. Of the various nitrogen containing heterocycles, bridgehead nitrogen heterocycles such as imidazo[1,2-a]pyridines 1 are of considerable interest owing to their biological activities. The imidazo[1, 2-a]pyridine moiety is seen in drugs such as zolpidem 2 (sedative) [4] and olprinone 3 (cardiotonic agent) [5]. 


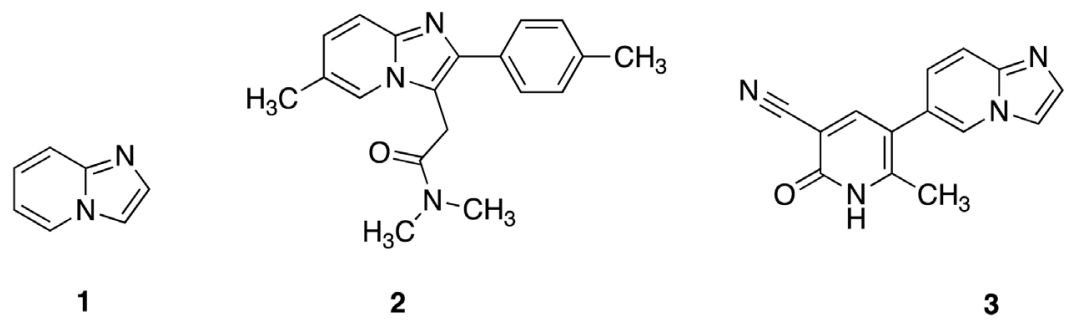

Several methods have been developed for the synthesis of a variety of imidazo[1, 2-a]pyridines [6]-[15]. In contrast, until recently there have been very few reports of the synthesis and biological activities of the corresponding saturated analogs such as hexahydroimidazo[1, 2-a]pyridines. One such report detailed a series of neonicotinoids of hexahydroimidazo[1,2-a]pyridines that were evaluated for their insecticidal activities [16]. Another report described the synthesis and antimicrobial activities of hexahydroimidazo[1,5-a]pyridinium bromides [17]. The lack of extensive reports on the biological activities of hexahydroimidazo[1, 2-a]pyridines is due in part to the limited methods available for their facile synthesis. Wang and co-workers reported the first efficient synthesis of hexahydroimidazo[1, 2-a]pyridines via a $p$-toluenesulfonic acid $(p-\mathrm{TsOH})$ catalyzed multicomponent reaction that utilized an aldehyde, ketone and 1,2-diaminoethane [18]. $\mathrm{Li}$ and co-workers report a similar synthesis using L-phenylalanine triflate as a catalyst, a compound that is not commercially available from a major supplier [19]. Neto and coworkers have reported a heteropolyacid containing ionic liquid-catalyzed multicomponent synthesis of hexahydroimidazo [1, 2-a]pyridine derivatives [20]. In this protocol, the heteropoly acid-ionic liquid catalyst must be synthesized. Tan and Wang have described the synthesis of hexahydroimidazo[1, 2-a]pyridines from condensation of a variety of substituted cinnamaldehydes, 1, 3-diketones and 1,2-diaminoethane catalyzed by acetic acid, which is rather corrosive [21]. Although a commonly used catalyst, $p$-toluenesulfonic acid $\left(p-\mathrm{TsOH} \cdot \mathrm{H}_{2} \mathrm{O}\right)$ is somewhat toxic $\left(\mathrm{LD}_{50}=2.48 \mathrm{~g} / \mathrm{kg}\right.$, rat oral) and highly irritating to the skin [22]. Due to our continued interest in developing environmentally-friendly synthesis especially using relatively nontoxic bismuth (III) compounds [23] [24] [25] [26] we sought to develop a bismuth (III) salt catalyzed multicomponent synthesis of hexahydroimidazo[1, 2-a]pyridines. Herein we report (Scheme 1) a bismuth (III) chloride $\mathrm{BiCl}_{3}$-catalyzed multicomponent synthesis of a series of hexahydroimidazo[1, 2-a]pyridines $6 \mathrm{a}-\mathbf{i}$ starting from an aldehyde $4 \mathrm{a}-\mathbf{i}$, ketone $5 \mathrm{a}-\mathbf{i}$ and 1 , 2-diaminoethane in $\mathrm{CH}_{3} \mathrm{OH}$.

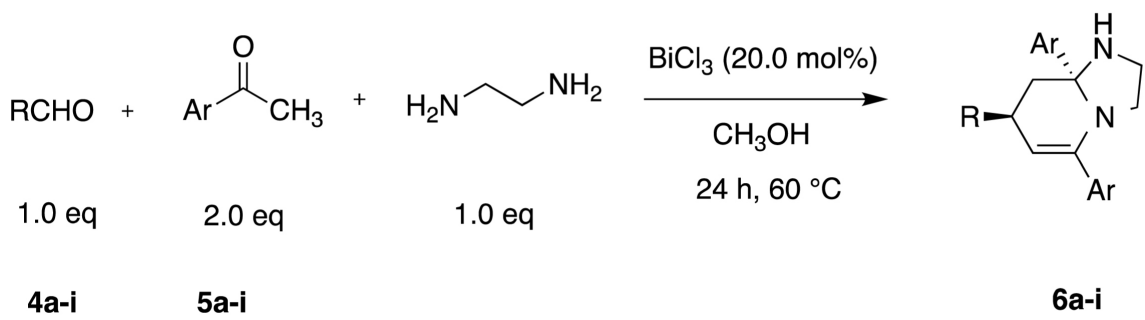

Scheme 1 . $\mathrm{BiCl}_{3}$-catalyzed multicomponent synthesis of hexahydro[1,2-a]pyridines. 
Table $1 . \mathrm{BiCl}_{3}$-catalyzed multicomponent synthesis of hexahydro[1, 2-a]pyridines. ${ }^{\mathrm{a}}$

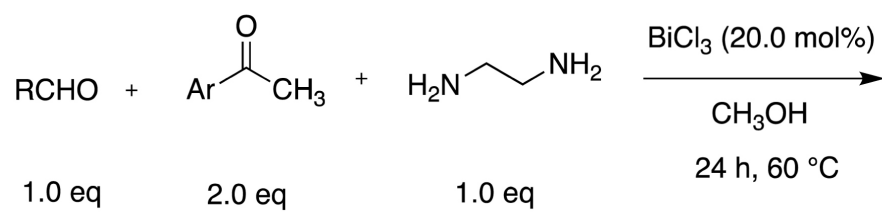

4a-i 5a-i

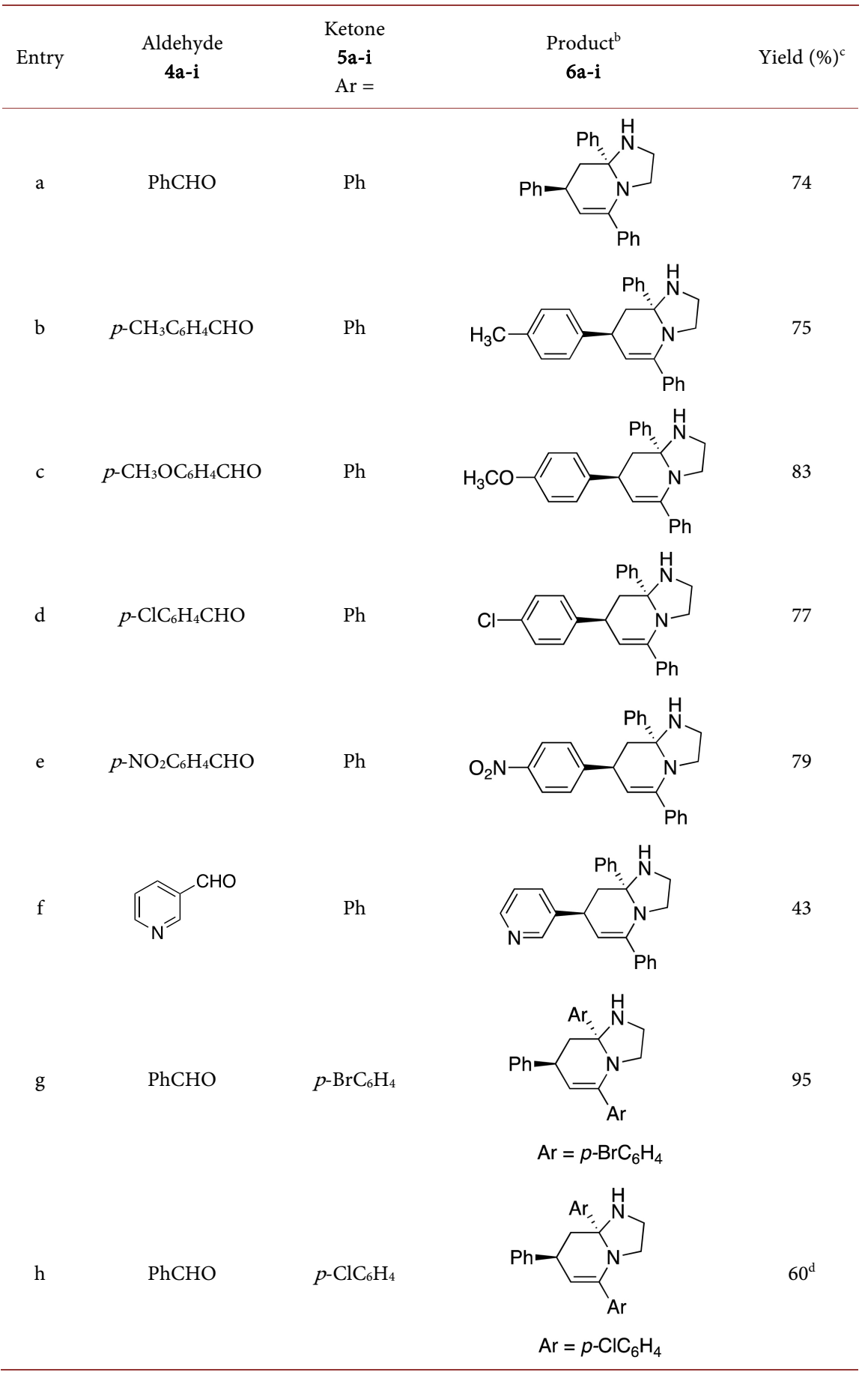

6a-i

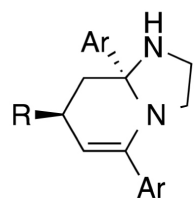




\section{Continued}

i $\quad P$ - $2 \mathrm{NO}_{2} \mathrm{C}_{6} \mathrm{H}_{4}$

${ }^{\mathrm{a}}$ Representative procedure: A solution of benzaldehyde $(0.50 \mathrm{~g}, 4.71 \mathrm{mmol}), 4$-bromoacetophenone $(1.87 \mathrm{~g}$, $9.42 \mathrm{mmol})$, and 1, 2-diaminoethane $(0.28 \mathrm{~g}, 4.71 \mathrm{mmol}, 0.31 \mathrm{~mL})$ in $\mathrm{CH}_{3} \mathrm{OH}(10.0 \mathrm{ml})$ was stirred at room temperature as $\mathrm{BiCl}_{3}(0.297 \mathrm{~g}, 0.942 \mathrm{mmol}, 20.0 \mathrm{~mol} \%)$ was added. The reaction mixture was then heated to $60^{\circ} \mathrm{C}$ using a temperature controlled hot plate. The reaction mixture acquired a yellow color. The progress of the reaction was monitored by TLC (40:60, EtOAc/heptane). After $24 \mathrm{~h}$, the reaction mixture was cooled to room temperature and methanol was removed using a rotary evaporator. The residue was then triturated with methanol $(5.0 \mathrm{~mL})$ and the resulting solid was collected by suction filtration to yield $2.28 \mathrm{~g}(95 \%)$ of a pale yellow solid (Table 1, entry g, product $6 \mathrm{~g}$ ). The identity of the product was confirmed by ${ }^{1} \mathrm{H}$ and ${ }^{13} \mathrm{C}$ NMR spectroscopy and High Resolution Mass Spectral (HRMS) data. 'Products were characterized by comparison of their ${ }^{1} \mathrm{H}$ and ${ }^{13} \mathrm{C}$ NMR spectrum with literature data [18] [19] and by HRMS data. ${ }^{~}$ Refers to yield of isolated product deemed to be $\geq 98 \%$ pure by ${ }^{1} \mathrm{H}$ and ${ }^{13} \mathrm{C}$ NMR spectroscopy. ${ }^{\mathrm{d}}$ Crude product was triturated twice with $\mathrm{CH}_{3} \mathrm{OH}$ (5.0 ml each).

Bismuth chloride is fairly nontoxic $\left(\mathrm{LD}_{50}=3.3 \mathrm{~g} / \mathrm{kg}\right.$, rat oral; compare $\mathrm{NaCl}$ $\mathrm{LD}_{50}=3.0 \mathrm{~g} / \mathrm{kg}$, rat oral) [27] [28], commercially available and relatively inexpensive. The methodology avoids an aqueous waste stream, and the product is isolated by trituration using methanol. Multicomponent reactions save steps, reduce waste, and add to the overall efficiency of the synthesis [29]. To discover the most efficient bismuth-based catalyst, several bismuth (III) salts (20.0 - 40.0 mol\%) were screened including $\mathrm{BiBr}_{3}, \mathrm{BiCl}_{3}$ and $\mathrm{Bi}(\mathrm{OTf})_{3}$ in a variety of solvents $\left(\mathrm{CH}_{3} \mathrm{OH}, \mathrm{CH}_{3} \mathrm{CH}_{2} \mathrm{OH}\right.$, ${ }^{\mathrm{P} r O H}, \mathrm{CH}_{2} \mathrm{Cl}_{2}$ and $\left.\mathrm{CH}_{3} \mathrm{CN}\right)$ at reflux temperatures. No reaction was seen at room temperature. Of these $\mathrm{BiCl}_{3}(20.0 \mathrm{~mol} \%)$ in $\mathrm{CH}_{3} \mathrm{OH}$ at $60^{\circ} \mathrm{C}$ was found to be the optimal condition. The stereochemistry of the product was assigned by comparison of the ${ }^{1} \mathrm{H}$ NMR spectra to literature spectra and found to be trans with respect to the aromatic ring of the aldehyde and ketone. None of the cis isomer could be detected in the ${ }^{1} \mathrm{H}$ NMR spectrum $(400 \mathrm{MHz}$ in $\mathrm{CDCl}_{3}$ ) of any of the products. The results of this study are summarized in Table 1. While ketones with an electron withdrawing group (entries $g$ - i) worked well, less satisfactory results were obtained with $p$-methylacetophenone (the product was $90 \%$ pure but could not be further purified even by multiple triturations or column chromatography).

In summary, a bismuth (III) chloride catalyzed multicomponent synthesis of hexahydroimidazo[1, 2-a]pyridines has been developed. The ease of workup, nontoxic nature of bismuth (III) compounds, and avoidance of an aqueous waste stream and chromatography are the attractive features of this method.

\section{Acknowledgements}

This material is based upon work supported by the National Science Foundation under CHE-1229133, which funded the purchase of a $400 \mathrm{MHz}$ NMR spectrometer. RM would like to acknowledge an Artistic and Scholarly grant from Illinois Wesleyan University. We are also grateful to an anonymous reviewer for 
insightful comments.

\section{Conflicts of Interest}

The authors declare no conflicts of interest regarding the publication of this paper.

\section{References}

[1] Cabrele, C. and Reiser, O. (2016) The Modern Face of Synthetic Heterocyclic Chemistry. The Journal of Organic Chemistry, 81, 10109-10125.

https://doi.org/10.1021/acs.joc.6b02034

[2] Taylor, A.P., Robinson, R.P., Fobian, Y.M., Blakemore, D.C., Jones, L.H. and Fadeyi, O. (2016) Modern Advances in Heterocyclic Chemistry in Drug Discovery. Organic \& Biomolecular Chemistry, 14, 6611-6637. https://doi.org/10.1039/C6OB00936K

[3] Kerru, N., Gummidi, L., Maddila, S., Gangu, K.K. and Jonnalagadda, S.B. (2020) A Review on Recent Advances in Nitrogen-Containing Molecules and Their Biological Applications. Molecules, 25, 1909. https://doi.org/10.3390/molecules25081909

[4] Hanson, S.M., Morlock, E.V., Satyshur, K.A. and Czajkowski, C. (2008) Structural Requirements for Eszopiclone and Zolpidem Binding to the GABAA Receptor Are Different. Journal of Medicinal Chemistry, 51, 7243-7252. https://doi.org/10.1021/jm800889m

[5] Enguehard-Gueiffier, C. and Gueiffier, A. (2007) Recent Progress in the Pharmacology of Imidazo[1,2-a]pyridines. Mini-Reviews in Medicinal Chemistry, 7, 888-899. https://doi.org/10.2174/138955707781662645

[6] Yan, R., Yan, H., Ma, C., et al. (2012) Cu(I)-Catalyzed Synthesis of Imidazo[1,2-a]pyridines from Aminopyridines and Nitroolefins Using Air as the Oxidant. Journal of Organic Chemistry, 77, 2024-2028. https://doi.org/10.1021/jo202447p

[7] Stasyuk, A.J., Banasiewicz, M., Cyrański, M.K. and Gryko, D.T. (2012) Imidazo[1,2-a]pyridines Susceptible to Excited State Intramolecular Proton Transfer: One-Pot Synthesis via an Ortoleva-King Reaction. Journal of Organic Chemistry, 77, 5552-5558. https://doi.org/10.1021/jo300643w

[8] Cai, Z., Wang, S. and Ji, S. (2013) Copper(I) Iodide/Boron Trifluoride Etherate-Cocatalyzed Aerobic Dehydrogenative Reactions Applied in the Synthesis of Substituted Heteroaromatic Imidazo[1,2-a]pyridines. Advanced Synthesis \& Catalysis, 355, 2686-2692. https://doi.org/10.1002/adsc.201300333

[9] Monir, K., Bagdi, A.K., Ghosh, M. and Hajra, A. (2014) Unprecedented Catalytic Activity of $\mathrm{Fe}\left(\mathrm{NO}_{3}\right)_{3} \cdot 9 \mathrm{H}_{2} \mathrm{O}$ : Regioselective Synthesis of 2-Nitroimidazopyridines via Oxidative Amination. Organic Letters, 16, 4630-4633.

https://doi.org/10.1021/ol502218u

[10] Bagdi, A.K., Rahman, M., Santra, S., Majee, A. and Hajra, A. (2013) Copper-Catalyzed Synthesis of Imidazo[1,2-a]pyridines through Tandem Imine Formation-Oxidative Cyclization under Ambient Air: One-Step Synthesis of Zolimidine on a Gram-Scale. Advanced Synthesis \& Catalysis, 355, 1741-1747. https://doi.org/10.1002/adsc.201300298

[11] Hiebel, M., Fall, Y., Scherrmann, M. and Berteina-Raboin, S. (2014) Straightforward Synthesis of Various 2,3-Diarylimidazo[1,2-a]pyridines in PEG400 Medium through One-Pot Condensation and C-H Arylation. European Journal of Organic Chemistry, 2014, 4643-4650. https://doi.org/10.1002/ejoc.201402079 
[12] Pan, S., Wang, G., Schinazi, R.F. and Zhao, K. (1998) Synthesis of Novel Isoxazolinyl Substituted Imidazo[1,2-a]pyridine C-Nucleoside Analogs. Tetrahedron Letters, 39, 8191-8194. https://doi.org/10.1016/S0040-4039(98)01872-3

[13] Lhassani, M., Chavignon, O., Chezal, J., et al. (1999) Synthesis and Antiviral Activity of Imidazo[1,2-a]pyridines. European Journal of Medicinal Chemistry, 34, 271-274. https://doi.org/10.1016/S0223-5234(99)80061-0

[14] Gudmundsson, K.S., Drach, J.C. and Townsend, L.B. (1997) Synthesis of Imidazo[1,2-a]pyridine C-Nucleosides with an Unexpected Site of Ribosylation. The Journal of Organic Chemistry, 62, 3453-3459. https://doi.org/10.1021/jo9619342

[15] Márton-Merész, M., Zára-Kaczián, E., Boros, S. and Mátyus, P. (1997) Cyclocondensation Reaction of a 1,5-diketone with 1,2-diamines. Journal of Heterocyclic Chemistry, 34, 1033-1036. https://doi.org/10.1002/jhet.5570340350

[16] Shao, X., Zhang, W., Peng, Y., Li, Z., Tian, Z. and Qian, X. (2008) cis-Nitromethylene Neonicotinoids as New Nicotinic Family: Synthesis, Structural Diversity, and Insecticidal Evaluation of Hexahydroimidazo[1,2-alpha]pyridine. Bioorganic \& Medicinal Chemistry Letters, 18, 6513-6516. https://doi.org/10.1016/j.bmcl.2008.10.048

[17] Türkmen, H., Ceyhan, N., Ülkü Karabay Yavaşoğlu, N., Özdemir, G. and Çetinkaya, B. (2011) Synthesis and Antimicrobial Activities of Hexahydroimidazo[1,5-a]pyridinium Bromides with Varying Benzyl Substituents. European Journal of Medicinal Chemistry, 46, 2895-2900. https://doi.org/10.1016/j.ejmech.2011.04.012

[18] Wang, R., Zhu, P., Lu, Y., Huang, F. and Hui, X. (2013) Brønsted Acid-Catalyzed Four-Component Cascade Reaction: Facile Synthesis of Hexahydroimidazo[1,2-a]pyridines. Advanced Synthesis \& Catalysis, 355, 87-92. https://doi.org/10.1002/adsc.201200145

[19] Jiang, J., Zhang, M., Wu, W., Lu, H., Shi, Y. and Li, J. (2018) L-Phenylalanine Triflate as Organocatalyst for Divergent Approaches to Trisubstituted Hexahydroimidazo[1,2-a]pyridine and 1,4-Diazepane Derivatives. Synlett, 29, 246-250. https://doi.org/10.1055/s-0036-1589115

[20] Alvim, H.G.O., Correa, J.R., Assumpçao, J.A.F., da Silva, W.A., Rodrigues, M.O., de Macedo, J.L., Fioramonte, M., Gozzo, F.C., Gatto, C.C. and Neto, B.A.D. (2018) Heteropolyacid-Containing Ionic Liquid-Catalyzed Multicomponent Synthesis of Bridgehead Nitrogen Heterocycles: Mechanisms and Mitochondrial Staining. The Journal of Organic Chemistry, 83, 4044-4053. https://doi.org/10.1021/acs.joc.8b00472

[21] Tan, H. and Wang, Y. (2020) Facile Synthesis of Novel Hexahydroimidazo[1,2-a]pyridine Derivatives by One-Pot, Multicomponent Reaction under Ambient Conditions. ACS Combinatorial Science, 22, 468-474. https://doi.org/10.1021/acscombsci.0c00105

[22] https://pubchem.ncbi.nlm.nih.gov/compound/P-Toluenesulfonic-acid\#section=Acu te-Effects

[23] Mohan, R. (2010) Green Bismuth. Nature Chemistry, 2, 336. https://doi.org/10.1038/nchem.609

[24] Salvador, J.A.R., Silvestre, S.M., Pinto, R.M.A., Santos, R.C. and LeRoux, C. (2012) New Applications for Bismuth(III) Salts in Organic Synthesis: From Bulk Chemicals to Steroid and Terpene Chemistry. Topics in Current Chemistry, 311, 143-178. https://doi.org/10.1007/128 2011 170

[25] Bothwell, J.M., Krabbe, S.W. and Mohan, R.S. (2011) Applications of Bismuth(III) Compounds in Organic Synthesis. Chemical Society Reviews, 40, 4649-4707. https://doi.org/10.1039/c0cs00206b 
[26] Ollevier, T. (2013) New Trends in Bismuth-Catalyzed Synthetic Transformations. Organic \& Biomolecular Chemistry, 11, 2740-2755. https://doi.org/10.1039/c3ob26537d

[27] https://pubchem.ncbi.nlm.nih.gov/compound/Bismuth-chloride-section=Acute-Eff ects

[28] https://pubchem.ncbi.nlm.nih.gov/compound/Sodium-chloride\#section=Acute-Effe cts

[29] Sunderhaus, J.D. and Martin, S.E. (2009) Applications of Multicomponent Reactions to the Synthesis of Diverse Heterocyclic Scaffolds. Chemistry: A European Journal, 15, 1300-1308. https://doi.org/10.1002/chem.200802140 